\title{
Relation of airway responsiveness to duration of work in a dusty environment
}

\author{
PIERRE ERNST, ROBERT E DALES, FATIMA NUNES, MARGARET R BECKLAKE \\ From the Pulmonary Research Laboratory, Department of Epidemiology and Biostatistics, McGill University; and $\vec{\omega}$ \\ the Department of Medicine, Respiratory Division, Montreal General Hospital, Montreal, Canada
}

ABSTRACT Health selection within a workforce has been found in several industries and appears to be more pronounced in dustier occupations. In this study of airway disease among workers exposed to asbestos and man made mineral fibres, 215 of 246 construction insulators 50 years old or less and $\vec{\sigma}$ currently working in the Montreal area were examined. Spirometry was completed successfully in 214 을 workers without known asbestosis and 207 underwent methacholine bronchoprovocation testing. $\rightarrow$ Airway responsiveness was expressed as $\mathrm{PC}_{15}$, the concentration of methacholine causing a $15 \%$ fall ${ }_{\mathbb{D}}$ in the forced expiratory volume in one second $\left(\mathrm{FEV}_{1}\right)$. Exposure to asbestos and synthetic mineral $\frac{O}{2}$ fibre dust was estimated from the total hours of work in the trade since first employment. After the $\stackrel{\equiv}{=}$ effect of age, height, and pack years of smoking had been taken into account, no relation was found ${ }_{-}$ between hours of work and any indices obtained from the forced expiratory manoeuvre $\left(\mathrm{FEV}_{1} / \mathrm{FVC}, \underset{\infty}{\infty}\right.$ MMF). After the effect of airway calibre $\left(F E_{1} / F V C\right)$, age, and pack years of cigarette consumption had been taken into account, airway responsiveness decreased as the total hours of work in the trade increased. These findings suggest that workers with greater levels of airway responsiveness are more sensitive to exposure in a dusty workplace and in consequence are less likely to continue. In studies of ${ }_{0}$ workforces a survivor effect of this nature will tend to weaken the relation between lung function $\frac{\circ}{\otimes}$ abnormality and occupational exposure.

\section{Introduction}

Health selection has been found in many occupational groups $^{1-4}$ and may attenuate exposure-response relationships observed in workers employed in hazardous industries. This bias is especially strong in cross sectional studies, where the workforce studied represents a survivor population. ${ }^{5}$ For these and other reasons, cautious interpretation of negative cross sectional studies has been recommended. ${ }^{6}$

Worker turnover appears to be especially increased in dusty jobs such as foundry work ${ }^{2}$ and employment in grain elevators. ${ }^{3}$ This negative health selection may also be related to individual susceptibility as reflected by atopy; this is the explanation proposed for the fact that grain elevator workers have a lower prevalence of atopy than civic workers. ${ }^{7}$ Such a selection bias not only may preclude the capability of a study to detect work related health effects but may actually produce paradoxical inverse associations between exposure

Address for reprint requests: Dr Pierre Ernst, Respiratory Division, Montreal General Hospital, 1650 Cedar, Montreal, Quebec, Canada H3G 1A4.

Accepted 25 November 1988 and disease, as has been described for allergy to laboratory animals. ${ }^{8}$

In the present study we report an inverse relation between exposure to mineral fibre dust and airway responsiveness, suggesting that bronchial hyper- $\underset{x}{\stackrel{D}{\nu}}$ responsiveness may be a factor determining health selection out of a dusty work environment.

\section{Methods}

\section{STUDY POPULATION}

The population base for the present study had been selected from respondents to a previous questionnaire survey of active construction insulators in the $\mathrm{N}$ Province of Quebec. ${ }^{9}$ From the responders to the $N$ questionnaire $(87 \%$ of the workforce) we invited the $N$ 246 insulators aged 20-50 years who lived in the Montreal area and did not have known asbestosis (five subjects receiving compensation) for further testing. Of this target population, $215(87 \%)$ came to our $\stackrel{9}{?}$ laboratory. Their mean age was 37 (SD 8) years. All 0 subjects were male.

MEASURES OF RESPIRATORY HEALTH All subjects completed the standardised American 
Thoracic Society respiratory symptom questionnaire, ${ }^{10}$ which was administered by an interviewer. Spirometry was carried out according to the Snowbird workshop criteria" ${ }^{11}$ with an Ohio 827 rolling seal spirometer (Ohio Medical Products, Madison, Wisconsin). The forced expiratory volume in one second $\left(F E V_{1}\right)$, the forced vital capacity (FVC), the maximal mid expiratory flow rate (MMF), and the maximal flow measured after $75 \%$ of the vital capacity had been expired $\left(\dot{V} \max _{25}\right)$ were recorded for analysis.

Methacholine bronchoprovocation testing was carried out in 207 subjects by the method described by Cockcroft. ${ }^{12}$ Briefly, during two minutes' tidal breathing the subjects first inhaled phosphate buffered saline, and then, at three minute intervals, concentrations of methacholine increasing from $2(0.5$ if asthma was suspected) to $32 \mathrm{mg} / \mathrm{ml}$. Aerosol was generated with a hand held Wright nebuliser, calibrated daily to produce $0 \cdot 14-0.16 \mathrm{ml} / \mathrm{min}$. $\mathrm{FEV}_{\text {, }}$ was measured 30 and 90 seconds after each dose and the test stopped if there was a $20 \%$ or greater fall in $\mathrm{FEV}_{1}$ or the highest concentration was used. The concentration required to produce a $15 \%$ fall in $\mathrm{FEV}_{1}\left(\mathrm{PC}_{15}\right)$ was taken from the log dose-response curve by linear interpolation of the last two points. The 126 subjects who did not reach $\mathrm{PC}_{15}$ were arbitraily assigned a value of $64 \mathrm{mg} / \mathrm{ml}$.

\section{ESTIMATES OF EXPOSURE}

Insulators in the Montreal area are employed through a union hiring hall, which assigns work from about 100 employers. Many of these firms are small and as a result hygiene surveys were most often not available. The estimate of exposure to dust and mineral fibre was based therefore on the duration of exposure only. Information was gathered from two sources. From 1974 to 1984 (the year the health measures were carried out) the annual hours worked in the trade had been recorded for a government pension plan. From union records we were able to calculate the number of hours worked during 1964-74 on the basis of dues paid and to obtain the date of first employment in the trade. For men who started working as insulators before 1964 an estimate of prior exposure was obtained by multiplying the mean annual hours of work from 1964 to 1984 by the number of years in the trade before 1984. The cumulative exposure was thus expressed as total hours worked in the trade. Dust measures are not generally available, but the work environment is uncontrolled and peak total dust exposures of $100 \mathrm{mg} /$ $\mathrm{m}^{3}$ or more are thought to be common, especially during demolition work and refurbishing of ships.

\section{ANALYSIS}

To adjust for differences between individuals in age and height, spirometric indices were expressed as percentages of predicted values on the basis of the normative equations of Knudson and colleagues. ${ }^{13}$ The determinants of lung function and airway responsiveness were analysed by linear regression. $\mathrm{PC}_{15}$ was expressed in log units. All analyses were carried out with BMDP statistical software. ${ }^{14}$

\section{Results}

The study population was divided into three roughly equal groups according to number of hours of work in the trade ("short" indicating < 13592 hours, "medium" 13 592-29 212 hours, and "long" > 29212 hours) (table 1). The distribution and mean values of the principal variables examined are displayed according to these exposure categories in table 1 . As the hours of work increased, so did average age and amount smoked (table 1). More ex-smokers are also found in the long exposure category. Both $\mathrm{FEV}_{1} \%$ predicted and $\mathrm{FEV}_{1} / \mathrm{FVC} \%$ were lower in the long exposure category. Airway responsiveness, measured as $\mathbf{P C}_{15}$, appears to lessen (that is, $\mathrm{PC}_{15}$ increases) with increasing length of exposure after adjustment for differences in starting airway calibre $\left(\mathrm{FEV}_{1} / \mathrm{FVC}\right)$.

The results of linear regression analysis used to examine the effect of smoking (pack years) and hours of employment (exposure estimate) on spirometric indices are shown in table 2 . There was a significant deterioration in lung function in relation to amount smoked but no such association between any spirometric index and hours of employment in the trade.

Regression analysis was used to examine the relation between airway responsiveness to methacholine $\left(\log \mathrm{PC}_{15}\right)$ and hours of employment considered as a continuous variable (table 3 ). Other factors that may potentially influence $\log \mathrm{PC}_{15}$ were included in the model to adjust for their influence and to enable the effect of hours of work to be assessed independently. $\mathrm{FEV}_{1} / \mathrm{FVC} \%$ was a strong determinant of airway responsiveness. Neither age nor smoking as measured in pack years significantly influenced $P_{15}$. There was a direct relation between $\mathrm{PC}_{15}$ and hours of work, which shows that $\mathrm{PC}_{15}$ increased (and bronchial responsiveness decreased) with duration of exposure at work (hours of employment in the trade). When age and pack years of cigarette smoking were excluded from the regression model the association between hours of work and $\mathrm{PC}_{15}$ was stronger $(\mathrm{p}=0.009)$.

The regression analysis relating hours of exposure to $\log \mathbf{P C}_{15}$ adjusted for $\mathrm{FEV}_{1} / \mathrm{FVC}$ was rerun after exclusion of 11 subjects whose chest radiographs were read as showing $1 / 0$ or greater profusion of small irregular opacities by either of two NIOSH certified B readers. The size of the decrease in airways responsiveness in relation to increasing hours of work was similar and remained statistically significant. 
Table 1 Characteristics of the subjects by exposure categories as estimated by number of hours of work in the trade

\begin{tabular}{|c|c|c|c|c|c|c|c|}
\hline \multirow[b]{3}{*}{ 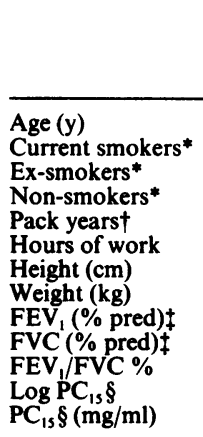 } & \multirow[b]{3}{*}{$\begin{array}{l}\text { Mean (SD) } \\
\text { No (\%) } \\
\text { No }(\%) \\
\text { No (\%) } \\
\text { Mean (SD) } \\
\text { Mean (SD) } \\
\text { Mean (SD) } \\
\text { Mean (SD) } \\
\text { Mean (SD) } \\
\text { Mean (SD) } \\
\text { Mean (SD) } \\
\text { Mean (SEM) } \\
\text { Mean }\end{array}$} & \multicolumn{2}{|c|}{ Short exposure } & \multicolumn{2}{|c|}{ Medium exposure } & \multicolumn{2}{|c|}{ Long exposure } \\
\hline & & \multicolumn{2}{|l|}{$(n=72)$} & \multicolumn{2}{|l|}{$(n=71)$} & \multicolumn{2}{|l|}{$(n=72)$} \\
\hline & & $\begin{array}{c}29 \cdot 7 \\
45 \\
12 \\
15 \\
13.9 \\
8154 \\
171.5 \\
75.6 \\
106.2 \\
109.4 \\
81.8 \\
1.284 \\
19.2\end{array}$ & $\begin{array}{c}(7 \cdot 1) \\
(63) \\
(17) \\
(21) \\
(11 \cdot 0) \\
(3714) \\
(6 \cdot 5) \\
(13 \cdot 7) \\
(11.9) \\
(10 \cdot 4) \\
(5 \cdot 7) \\
(0.064)\end{array}$ & $\begin{array}{c}35.9 \\
49 \\
18 \\
4 \\
18 \cdot 0 \\
21349 \\
169 \cdot 7 \\
74 \cdot 7 \\
104 \cdot 8 \\
107.7 \\
81 \cdot 0 \\
1.405 \\
25.4\end{array}$ & $\begin{array}{c}(4 \cdot 7) \\
(69) \\
(25) \\
(6) \\
(10 \cdot 0) \\
(4571) \\
(6 \cdot 0) \\
(12 \cdot 1) \\
(14 \cdot 6) \\
(12.9) \\
(5 \cdot 9) \\
(0.065)\end{array}$ & $\begin{array}{c}45 \cdot 3 \\
37 \\
27 \\
8 \\
22 \cdot 4 \\
49318 \\
168 \cdot 3 \\
74 \cdot 9 \\
102 \cdot 9 \\
107 \cdot 8 \\
78 \cdot 8 \\
1.535 \\
34 \cdot 3\end{array}$ & $\begin{array}{c}(3.4) \\
(51) \\
(38) \\
(11) \\
(11.9) \\
(10627) \\
(5 \cdot 8) \\
(11 \cdot 1) \\
(14 \cdot 1) \\
(12.9) \\
(6.6) \\
5 \quad(0.064) \\
\end{array}$ \\
\hline
\end{tabular}

*"Non-smokers" had never smoked as much as 20 packs of cigarettes or $\mathbf{4 0 0} \mathrm{g}$ of tobacco in a lifetime or one cigarette a day for a year; "exsmokers" had completely refrained from smoking for at least one month. All other subjects were classified as current smokers.

tOne pack year is the equivalent of smoking 25 cigarettes a day for one year. Non-smokers were excluded in calculated mean values in each exposure category.

\pm Predicted values were derived from the equations of Knudson et al. ${ }^{13}$

$\$ \mathrm{Means}$ and standard errors for $\log \mathrm{PC}_{15}$ were calculated by analysis of covariance to adjust for differences between individuals and groups in FEV $/$ FVC. PC $_{15}$ was obtained by converting the mean $\log \mathbf{P C}_{15}$ in each group to its arithmetic value.

FEV - one second forced expiratory volume; FVC - forced vital capacity; PC $_{15}$-provocative concentration of methacholine causing a $15 \%$ fall in FEV,

Table 2 Spirometric values (\% predicted) in relation to cumulative smoking history and hours of employment

\begin{tabular}{|c|c|c|}
\hline & Smoking (pack years)* & Hours of employment \\
\hline $\begin{array}{l}\text { FEV }_{1} \\
\text { FVC } \\
\text { MMF } \\
\dot{V}_{\max } \max _{25}\end{array}$ & $\begin{array}{ll}\beta \text { coefficient } \dagger & p \\
-0.280 & 0.0001 \\
-0.200 & 0.005 \\
-0.289 & 0.0001 \\
-0.291 & 0.0001\end{array}$ & $\begin{array}{ll}\beta \text { coefficient }+ & p \\
-0.023 & 0.73 \\
-0.015 & 0.83 \\
-0.012 & 0.86 \\
-0.062 & 0.34\end{array}$ \\
\hline
\end{tabular}

* One pack year equals 25 cigarettes per day for one year or the equivalent (one packet contains 25 cigarettes in Canada).

tStandardised regression coefficients from the linear regression analysis of lung function (the dependent variable) on smoking and hours of employment (the independent variables).

MMF-maximum mid expiratory flow; $\max _{25}$-maximum flow after $75 \%$ of vital capacity expired. Other abbreviations as in table 1 .

Table 3 Determinants of airway responsiveness to methacholine

\begin{tabular}{lcl}
\hline $\begin{array}{l}\text { Dependent variable log } P C_{15} \\
\text { Independent variables (below) }\end{array}$ & $\beta$ coefficient $\dagger$ & $p$ \\
\hline FEV 1 FVC \% & 0.548 & 0.000 \\
Age (y) & -0.082 & 0.45 \\
Smoking (pack years) & -0.048 & 0.43 \\
Hours of work & 0.227 & 0.02 \\
$\mathrm{R}^{2}: 0.32 *$ & & \\
\hline
\end{tabular}

*The $\mathbf{R}^{2}$ represents the proportion of the variability in the dependent variable explained by the independent variables included in the model.

†Standardised regression coefficient.

\section{Discussion}

In an active workforce exposed to asbestos and synthetic mineral fibres we observed a lower degree of bronchial responsiveness with increasing number of hours worked after adjusting for starting airway calibre. There are several plausible biological explanations for our results. Firstly, exposure to dust at work may have caused mucus hypersecretion. ${ }^{15}$ In animals mucus hypersecretion secondary to cigarette smoke ${ }^{16}$ or to sulphur dioxide inhalation ${ }^{17}$ results in a decreased response to inhaled methacholine, apparently because of an alteration of the epithelial barrier. This does not appear to be the case in man, however-exposure to cigarette smoke ${ }^{1819}$ or sulphur dioxide ${ }^{20}$ or the presence of chronic bronchitis ${ }^{21} 22$ has usually been associated with an increase in bronchial responsiveness. As was the case in the present study, much of the relation between chronic airway disease and bronchial responsiveness can be explained by a reduction in starting airway calibre, ${ }^{212324}$ although airway inflammation may also independently increase bronchial responsiveness. ${ }^{25} \mathrm{We}$ observed no difference in airway responsiveness $\left(\mathrm{PC}_{15}\right)$, however, between the men with and the men without chronic sputum production (data not shown), and mucus hypersecretion therefore appears unlikely to have been responsible for the lower airway responsiveness in relation to number of hours of work in a dusty environment.

According to the Dutch hypothesis, an asthmatic predisposition is a risk factor for the development of $\varrho$ chronic airflow limitation. ${ }^{26}$ Indeed, bronchial $\stackrel{\mathcal{D}}{\overparen{D}}$ hyperresponsiveness has been found in subjects show- $\stackrel{\mathcal{\infty}}{\rightarrow}$ ing an excessive decline in lung function over time. ${ }^{27} 28$ Selection out of a workforce because of respiratory ill health has been found in several groups working in dusty environments..$^{1-3}$ It is certainly conceivable that this health selection is due in part to the symptoms of 
airway hyperresponsiveness. Bronchial hyperresponsiveness may also underlie the association between poorly reproducible spirometric results and increased morbidity and mortality described in several dust exposed cohorts. ${ }^{29}{ }^{30}$ Thus an inverse relation between bronchial hyperresponsiveness and exposure to dust at work may be analogous to the "healthy smoker effect" that is apparent from the non-random taking up of the smoking habit ${ }^{31}$ and the better lung function found in young smokers than in non-smokers in some studies. ${ }^{32}$

The concentration of methacholine producing a $15 \%$ drop in $\mathrm{FEV}_{1}\left(\mathrm{PC}_{15}\right)$ was our a priori choice for expressing airway responsiveness. It is more sensitive than but as reproducible as $\mathrm{PC}_{20}{ }^{33}$ the concentration producing a $20 \%$ fall in $\mathrm{FEV}_{1}$ which is commonly used in clinical practice. We believe $\mathrm{PC}_{15}$ to be an appropriate choice for studies of workforces exposed to dusts where asthma is not a concern and where individuals with asthma may actually be fewer than in the general population. ${ }^{7}$ The greater the number of subjects who actually have a measurable $\mathbf{P C}_{15}$ (as distinct from $\mathrm{PC}_{20}$ ) the greater the power of the study.

After we had accounted for the effect of airway calibre there was no relation between airway responsiveness $\left(\mathrm{PC}_{15}\right)$ and cumulative cigarette smoking (pack years). This is consistent with some ${ }^{23}$ but not other ${ }^{25}$ previous reports, and may be partly due to the use of methacholine as the bronchoconstricting agent. ${ }^{34}$

In conclusion, our results suggest that the development of airway hyperresponsiveness may bring about a self sought and probably self protective decrease in exposure to a dusty work environment and may be a factor favouring the selection of subjects out of such a workforce. Such health selection would reduce the likelihood of detecting an effect of asbestos and synthetic mineral fibre exposure on bronchial airflow measurements.

We thank the officers and members of the International Association of Heat and Frost Insulators and Asbestos Workers, Local 58, for their enthusiastic participation.

\section{References}

1 Fox AJ, Collier PF. Low mortality rates in industrial cohort studies due to selection for work and survival in the industry. Br J Prev Soc Med 1976;30:225-30.

2 Koskela R-S, Luoma K, Hernberg S. Turnover and health selection among foundry workers. Scand J Work Environ Health 1976;2(suppl 1):90-105.

3 Broder I, Corey P, Davies G, et al. Longitudinal study of grain elevator and control workers with demonstration of healthy worker effect. JOM 1985;27:873-80.

4 Koskela R-S, Jarvinen E, Korhonen H, Mutanen P. Health selection among metal workers. Scand J Work Environ Health 1983;9:155-61.

5 McDonald JC. Epidemiology. In: Weill H, Turner-
Warwick M, eds. Occupational lung diseases: research approaches and methods. New York: M Dekker, 1981: 373-403.

6 Mur JM, Cavelier C. Significance of cross-sectional surveys in occupational epidemiology. Scand J Environ Work Health 1982;8(suppl 1):24-5.

7 Broder I, Mintz S, Hutcheon M, et al. Comparison of respiratory variables in grain elevator workers and civic outside workers of Thunder Bay, Canada. Am Rev Respir Dis 1979;119:193-203.

8 Lutsky II, Newman I. Laboratory animal danger allergy: 1. An occupational disease. Ann Allergy 1975;35:201-5.

9 Ernst P, Shapiro S, Dales RE, Becklake MR. Determinants of respiratory symptoms in insulation workers exposed to asbestos and synthetic mineral fibers. $\mathrm{Br} J$ Ind Med 1987;44:90-5.

10 Ferris BG Jr. Epidemiology standardization project. Am Rev Respir Dis 1978;118(2, part 2):1-120.

11 American Thoracic Society. ATS statement. Snowbird workshop on standardization of spirometry. Am Rev Respir Dis 1979;119:831-8.

12 Cockcroft DW. In: Hargreave FE, Woolcock AJ, eds Airway responsiveness: measurement and interpretation. Mississauga: Astra Pharmaceuticals Canada Ltd., 1985:22-8.

13 Knudson RJ, Lebowitz MD, Holberg CJ, Burrows B. Changes in the normal maximal expiratory flowvolume curve with growth and aging. Am Rev Respir Dis 1983;127:725-34.

14 Dixon WJ, ed. BMDP statistical software. Berkeley: University of California Press, 1983.

15 Morgan WKC. Industrial bronchitis. Br J Ind Med 1978; 35:285-91.

16 DeSanctis GT, Kelly SM, Saetta MP, et al. Hyporesponsiveness to aerosolized but not to infused methacholine in cigarette-smoking dogs. Am Rev Respir Dis 1987; 135:338-44.

17 Shore SA, Kariya ST, Anderson K, et al. Sulfur-dioxide induced bronchitis in dogs. Effects on airway responsiveness to inhaled and intravenously administered methacholine. Am Rev Respir Dis 1987;135:840-7.

18 Gerrard JW, Cockcroft DW, Mink JT, Cotton DJ, Poonawal R, Dosman JA. Increased non-specific bronchial reactivity in cigarette smokers with normal lung function. Am Rev Respir Dis 1980;122:577-81.

19 Malo JL, Filiatrault S, Martin RR. Bronchial responsiveness in inhaled methacholine in young asymptomatic smokers. J Appl Physiol 1982;52:1464-70.

20 Harkonen $\mathrm{H}$, Nordman $\mathrm{H}$, Korhonen $\mathrm{O}$, Winbald I. Long term effects of exposure to sulfur dioxide-lung function four years after a pyrite dust explosion. Am Rev Respir Dis 1983;128:890-3.

21 Ramsdell JW, Nachtwey FJ, Moser KM. Bronchial hyperreactivity in chronic obstructive bronchitis. $\mathrm{Am}$ Rev Respir Dis 1982;126:829-32.

22 Bahous J, Cartier A, Ouimet G, Pineau L, Malo J-L. Non-allergic bronchial hyperexcitability in chronic bronchitis. Am Rev Respir Dis 1984;129:216-20.

23 Ramsdale EH, Morris MM, Roberts RS, Hargreave FE. Bronchial responsiveness to methacholine in chronic bronchitis: relationship to airflow obstruction and cold air responsiveness. Thorax 1984;39:912-8.

24 Yan K, Salome CM, Woolcock AJ. Prevalence and 
nature of bronchial hyperresponsiveness in subjects with chronic obstructive pulmonary disease. $\mathrm{Am} \mathrm{Rev}$ Respir Dis 1985;132:25-9.

25 Mullen JBM, Wiggs BR, Wright JL, Hogg JC, Paré PD. Non-specific airway reactivity in cigarette smokers. Relationship to airway pathology and baseline lung function. Am Rev Respir Dis 1986;133:120-5.

26 Orie NGM, Sluiter HJ, eds. Bronchitis. Assen, The Netherlands: Royal Van Gorcum, 1961:43-59.

27 Taylor RG, Joyce H, Cross E, Holland F, Pride WB. Bronchial reactivity to inhaled histamine and annual rate of decline in $\mathrm{FEV}_{1}$ in male smokers and exsmokers. Thorax 1985;40:9-16.

28 Tabona M, Chan-Yeung M, Enarson D, Maclean L, Dorken E, Schulzer M. Host factors affecting longitudinal decline in lung function among grain elevator workers. Chest 1984;85:782-6.

29 Eisen EA, Oliver LC, Christiani DE, Robins JM, Wegman DH. Effects of spirometry standards in two occupational cohorts. Am Rev Respir Dis 1985;
132: $120-4$.

30 Kellie SE, Attfield MD, Hankinson JL, Castellan RM. Spirometry variability criteria. Association with respiratory morbidity and mortality in a cohort of coal miners. Am J Epidemiol 1987;125:437-44.

31 Tashkin DP, Clark VA, Coulson AH, et al. Comparison of lung function in young non-smokers and smokers before and after initiation of the smoking habit-a prospective study. Am Rev Respir Dis 1983;128:12-6.

32 Leech JA, Ghezzo H, Stevens D, Becklake MR. Respiratory pressures and function in young adults. Am Rev Respir Dis 1983;128:17-23.

33 Neijens HJ, Hofkamp M, Degenhart HJ, Kerrebijn KF. Bronchial responsiveness as a function of inhaled histamine and the methods of measurement. Bull Europ Physiopathol Respir 1982;18:427-38.

34 Du Toit JI, Woolcock AJ, Salome CM, Sundrum R, Black JL. Characteristics of bronchial hyperresponsiveness in smokers with chronic air-flow limitation. Am Rev Respir Dis 1986;134:498-501. 